\title{
Comparative study between chemostat and batch reactors to quantify membrane permeability changes on bacteria exposed to silver nanoparticles
}

\author{
Nelson M. Anaya ${ }^{\mathrm{a}}$, Fatemeh Faghihzadeha ${ }^{\mathrm{a}}$, Nasim Ganji ${ }^{\mathrm{b}}$, Geoff Bothun ${ }^{\mathrm{b}}$, Vinka Oyanedel-Craver ${ }^{\mathrm{a}^{*}}$ \\ ${ }^{a}$ Department of Civil and Environmental Engineering. University of Rhode Island, 1 Lippitt Rd., Bliss hall 203. \\ Kingston, Rhode Island 02881, United States. \\ ${ }^{\mathrm{b}}$ Department of Chemical Engineering. University of Rhode Island, 16 Greenhouse Rd., Crawford hall. Kingston, \\ Rhode Island 02881, United States \\ *Corresponding author: craver@uri.edu
}

\begin{abstract}
Continuous and batch reactors were used to assess the effect of the exposure of caseincoated silver nanoparticles (AgNPs) on Escherichia coli (E. coli). Additionally, E. coli membrane extracts, membrane permeability and Langmuir film balance assays were used to determine integrity and changes in lipid composition in response to AgNPs exposure.

Results showed that batch conditions were not appropriate for the tests due to the production of exopolymeric substances (EPS) during the growth phase. After 5 hours of contact between AgNPs and the used growth media containing EPS, the nanoparticles increased in size from $86 \mathrm{~nm}$ to $282 \mathrm{~nm}$ reducing the stability and thus limiting cellnanoparticle interactions. AgNPs reduced E. coli growth by $20 \%$ at $1 \mathrm{mg} / \mathrm{L}$, in terms of Optical Density 670 (OD670), while no effect was detected at 15mg/L. At 50mg/L of AgNPs was not possible to perform the test due to aggregation and sedimentation of the nanoparticles. Membrane extract assays showed that at $1 \mathrm{mg} / \mathrm{L} \mathrm{AgNPs} \mathrm{had} \mathrm{a} \mathrm{greater} \mathrm{change}$ in area $\left(-4.4 \mathrm{~cm}^{2}\right)$ on bacteria compared to $15 \mathrm{mg} / \mathrm{L}\left(-4.0 \mathrm{~cm}^{2}\right)$. This area increment suggested that membrane disruption caused by AgNPs had a stabilizing/rigidifying effect where the cells responded by shifting their lipid composition to more unsaturated lipids to counteract membrane rigidification.
\end{abstract}


In chemostats, the constant inflow of fresh media and aeration resulted in less AgNPs aggregation, thus increased the AgNPs-bacteria interactions, in comparison to batch conditions. AgNPs at $1 \mathrm{mg} / \mathrm{L}, 15 \mathrm{mg} / \mathrm{L}$, and $50 \mathrm{mg} / \mathrm{L}$ inhibited the growth (OD670 reduction) by $0 \%, 11 \%$ and $16.3 \%$, respectively. Membrane extracts exposed to $1 \mathrm{mg} / \mathrm{L}, 15 \mathrm{mg} / \mathrm{L}$, and $50 \mathrm{mg} / \mathrm{L}$ of AgNPs required greater changes in area by $-0.5 \mathrm{~cm}^{2}, 2.7 \mathrm{~cm}^{2}$ and $3.6 \mathrm{~cm}^{2}$, respectively, indicating that the bacterial membranes were disrupted and bacteria responded by synthesizing lipids that stabilize or strengthen membranes.

This study showed that the chemostat is more appropriate for the testing of nanotoxicological effects when testing bacteria at growing conditions.

Keywords: Silver nanoparticles, growth inhibition, surface tension, permeability, chemostat reactors, Langmuir Blodgett test

\section{INTRODUCTION}

Silver nanoparticles (AgNPs) are one of the most commonly used nanomaterials in consumer products due to their antimicrobial properties (Kasaraneni et al., 2014; Schifman et al., 2015, Zhang and Oyanedel-Craver, 2013, 2012). While the antimicrobial properties of AgNPs are beneficial for several medical applications (Prabhu and Poulose, 2012) (Li et al., 2008), the accidental release of them can negatively affect bacterial populations responsible to important biogeochemical cycles (Marambio-Jones and Hoek, 2010)(Panyala et al., 2008). Several studies have demonstrated the antimicrobial properties of AgNPs and the critical role of membrane integrity; however, changes in the composition and properties of bacterial membranes due to AgNPs exposure, is not yet completely understood (Guzmán et al., 2012). 
Cell membrane acts as a permeability barrier to the cytoplasm and is able to regulate the transport of macro- and micro- nutrients from the media to the cytoplasm as well as the osmotic pressure through the plasma membrane. The osmotic pressure influences the integrity and hydration of cells and their intracellular compartments. Inflowing of water and swelling is governed by a decrease in external osmotic pressure (Wood, 2015), whereas an increase in osmotic pressure results in outflowing of water and dehydration. However, water fluxes coming simultaneously from opposite directions can disturb several cellular properties, including cell volume, turgor pressure, strain and cytoplasmatic membrane tension. Attenuation of water fluxes, by the accumulation or release of solutes, is one mechanism by which cells will respond to changes in external osmotic pressure (Wood, 2015).

AgNPs can damage bacterial membrane via three mechanisms. First, the electrostatic interaction between cell membranes and nanoparticles can interrupt transmembrane electron transfer, and produce break formation (pit formation). Through this mechanism, AgNPs can also penetrate into the cell membrane producing an increase in the permeability, resulting in an uncontrolled plasma-membrane transport and even leading to cell death (Prabhu and Poulose, 2012). Secondly, AgNPs can release silver ions $\left(\mathrm{Ag}^{+}\right)$through cooperative oxidation with both protons and dissolved $\mathrm{O}_{2}$ (Liu and Hurt, 2010). $\mathrm{Ag}^{+}$can be transported in the bacterial membrane by the potential disruption of nanoparticles to the cell wall and membrane. Bacterial membrane permeability can be affected by the $\mathrm{Ag}^{+}$mechanism described above and cause the release of lipopolysaccharides (LPS) and membrane proteins (Losasso et al., 2014). Moreover, $\mathrm{Ag}^{+}$can cause the release of phosphate, mannitol, succinate, proline and glutamine from the cytoplasm and disrupt the respiration cycle by inhibiting the uptake of phosphorous, thus impairing the 
formation of energy-regulating compounds such as nicotinamide adenine dinucleotide (NADH) or damaging molecules, such as DNA (Rai et al., 2012).

Finally, the interaction between $\mathrm{Ag}^{+}$and thiol groups in proteins, in addition to inactivating the respiratory enzymes, can lead to the production of undesirable compounds, such as reactive oxygen species (ROS) (Li et al., 2008). Intracellular oxidative stress can then occur as a result of high amounts of ROS, which can cause changes in the permeability of the cell membrane, protein structure, mitochondrial activity, and DNA replication (Manke et al., 2013) (Eckhardt et al., 2013) (Prabhu and Poulose, 2012).

Bioreactors are used to grow bacteria in continuous or batch mode. Previous studies have provided insight into the potential use of continuous reactors (chemostats) to assess stress conditions on bacteria. The effect of $\mathrm{pH}$, osmotic stress, antibiotic resistance, and temperatures on bacteria have been studied extensively using chemostats (King et al., 2006) (Leenheer and Cogan, 2008). In chemostats, bacteria response in terms of cell growth and adaptation can be studied under single and multiple conditions, such as competition with nutrient recycling and antibiotic treatment (Lin et al., 2012) (Ziv et al., 2013)(Miller et al., 2013) (Gresham and Hong, 2015). Comparatively, batch reactors have been used broadly to quantify the antimicrobial properties of nanoparticles in terms of their impacts on metabolic functions and cell structure such as, viability, membrane permeation, growth and respiration (Anaya et al., 2015; Mirzajani et al., 2011; Roe et al., 2008; Choi et al., 2008; Zhang and Oyanedel-Craver, 2013, 2012).

The objective of this work is to compare batch and chemostat systems to assess the toxicity of casein-coated AgNPs on Escherichia coli (E. coli) based on membrane permeability, which is an indicator of membrane integrity and cells ability to adapt its membrane lipid composition. The effects of AgNPs on E coli have been widely studied, and thus the results 
produced in this research can be compared to those obtained previously. Spherical casein-coated AgNPs have been characterized and used in our research group and others (Zhang et al., 2012) (Kvitek et al., 2009). To our knowledge, cell membrane changes due to nanoparticle exposure have not been studied and compared as a function of bacterial growth conditions, batch or continuous growth. The rate of substrate utilization and product formation are dependent on the growth conditions and can influence the nature and magnitude of the effect of AgNPs on the cell membrane, and thus, bacterial metabolism.

To gain additional mechanistic insight into AgNPs-membrane interactions, we have coupled bioreactor experiments with Langmuir film balance analysis of lipid monolayers formed using E. coli membrane extracts. Film balance studies have used to examine nanoparticle interactions with synthetic lipid monolayers, but they have not been used to examine lipid monolayers from membrane extracts to assess AgNPs exposure (Guzmán et al., 2013; Peetla and Labhasetwar, 2008; Torrano et al., 2013). Monolayer film balance analysis yields surface pressure-area isotherms that can be used to assess the biophysical properties of lipids as well as lipid composition (Kurniawan et al., 2013) (Bothun et al., 2016; Venkataramanan et al., 2014). The influence of the bacteria growth conditions coupled with membrane permeability assays and membrane extract analysis provides new methodologies and testing conditions that may be used to more accurately examine the response of microorganisms to nanoparticle exposure.

\section{MATERIALS AND METHODS}

\subsection{Materials}

A non-pathogenic strain of E. coli K-12 (ATCC 23716) was selected for this study. E. coli is a gram-negative bacterium that has been extensively used in nanotoxicological studies (Venieri et al., 2014; Choi et al., 2008; Pratap Reddy et al., 2007). Reagents used to prepare the 
growth media for the bacteria — sodium chloride $(\mathrm{NaCl})$, yeast extract, and tryptone —; and phosphate buffer solution (PBS) - monobasic potassium phosphate, dibasic potassium phosphate and Ethylenediaminetetraacetic acid (EDTA) — were purchased from Sigma Aldrich. The chemical oxygen demand (COD) was measured using the TNT 822 kit from Hach Company. Dichloromethane, methanol, and chloroform used for membrane extraction and Langmuir Blodgett tests were obtained from Sigma Aldrich. SYTO 9 and propidium iodide used for cell membrane permeation were purchased from Invitrogen. Standard casein-coated AgNPs were obtained from Argenol Company, Spain.

\subsection{Methods}

\subsubsection{Nanoparticle characterization}

Hydrodynamic diameter and zeta potential were measured using dynamic light scattering (DLS) (Malvern Zetasizer Nano ZS, ZEN 3600). Inductively-coupled plasma spectroscopy (ICPOES optima 3100, Perkin Elmer) was used to measure the concentrations of AgNPs and $\mathrm{Ag}^{+}$ ions. Digestion in 2\% nitric acid was required for each sample before analysis. The ionic release from AgNPs at each condition was quantified as per Liu and Hurt (2010) using centrifugal ultrafilter devices (ultra-4,3K) purchased from Amicon. Three concentrations of AgNPs -1 $\mathrm{mg} / \mathrm{L}, 15 \mathrm{mg} / \mathrm{L}$ and $50 \mathrm{mg} / \mathrm{L}$ - were used to assess the changes in permeation and surface pressure in chemostat and batch reactors.

\subsubsection{Growth media and Bacteria culturing}

Lysogeny Broth Miller (LB) growth media consisted of $10 \mathrm{~g} / \mathrm{L} \mathrm{NaCl}, 5 \mathrm{~g} / \mathrm{L}$ yeast extract, and $10 \mathrm{~g} / \mathrm{L}$ tryptone (Reddy et al., 2007). Culture media was immediately autoclaved after preparation. For each experiment, a fresh bacteria culture was grown for 12 hours in the LB media at $37^{\circ} \mathrm{C}$. After that, optical density at a wavelength of $670 \mathrm{~nm}$ (OD670) was measured 
separating the bacteria from the culture media by centrifuging it at $2500 \mathrm{rpm}$ for $15 \mathrm{~min}$ and additional pellet resuspension in PBS (10\%) solution (Zhang and Oyanedel-Craver 2012). PBS (10\%) consisted of $1.12 \mathrm{~g} / \mathrm{L} \mathrm{K}_{2} \mathrm{HPO}_{4}, 0.48 \mathrm{~g} / \mathrm{L}$ monobasic potassium phosphate $\mathrm{KH}_{2} \mathrm{PO}_{4}$ and $0.002 \mathrm{~g} / \mathrm{L}$ EDTA. The biomass concentration was measured indirectly through chemical oxygen demand (COD) using Hach TNT 822 with a Hach DR 2800 spectrometer. OD670 was also used to follow the bacteria concentration evolution in each reactor. An optical density reading at this wavelength indirectly reflects the number of bacteria.

\subsubsection{Bioreactors}

A multiplexed chemostat arrays and a Synergy TM MX microplate reader (BIOTEK, VT) were used to perform the continuous and batch tests, respectively. All experiments were run in duplicate, including controls to detect contamination (media with no bacteria), non exposed condition (media plus bacteria) and exposed condition (media plus bacteria+AgNPs). The ratio between number of AgNPs (estimated from DLS size distribution measurements) and bacteria was kept constant for both chemostat and batch reactors to compare the bacteria response. However, it will change either through the influent of fresh media in the chemostat or growth of bacteria in the case of batch test

\subsubsection{Chemostats}

Figure 1 shows a schematic of the multiplex chemostat arrangement. The bioreactors and sample vessels were sterilized twice before use. The array consisted of six small vessels fed with LB medium and air. Two needles were attached to each vessel for air and culture media injection. An airflow of $0.7 \mathrm{~L} / \mathrm{min}$ was passed through a trap to remove humidity followed by a $0.2 \mu \mathrm{m}$ filter and pumped into the bioreactors. The airflow maintained a DO of $0.6 \mathrm{mg} / \mathrm{L}$ inside 
the reactors. A peristaltic pump was used to feed the reactors with the culture media at a rate of $0.2 \mathrm{~mL} / \mathrm{min}$, setting up the dilution factor at $0.6 \mathrm{~h}^{-1}$. Each bioreactor was inoculated with $300 \mu \mathrm{L}$ of fresh bacteria solution. After 12.5 hours steady state conditions were achieved in terms of biomass concentration. Temperature and $\mathrm{pH}$ conditions at steady state were $37^{\circ} \mathrm{C}$ and a $\mathrm{pH}$ of 7.3 \pm 0.3 , respectively. After reaching stable conditions, AgNPs were injected to achieve the desired concentrations inside the vessel. Separate experiments were run with $1 \mathrm{mg} / \mathrm{L}, 15 \mathrm{mg} / \mathrm{L}$ and 50 mg/L of AgNPs. OD670 and COD were used to follow the evolution of the bacteria concentration after the disturbance.

Samples were taken from each reactor every 2.5 hours using the sample needle (Figure 1). $\mathrm{pH}$ was measured immediately after sample collection. The OD670 was measured using a spectrometer once the culture media had been removed from the sample through centrifugation and resuspending the bacteria pellet in $10 \mathrm{~mL}$ of PBS (10\%). 


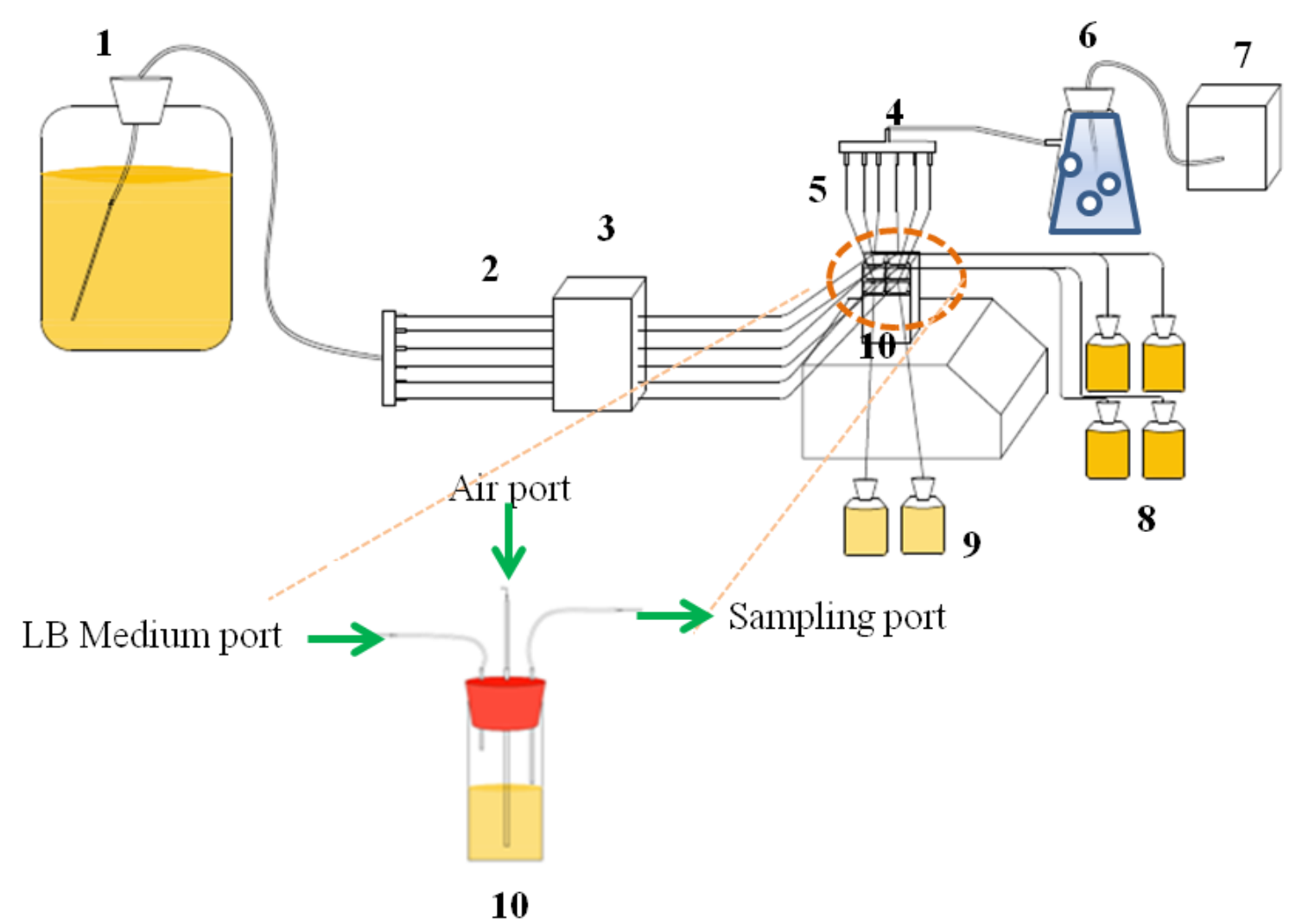

Figure 1: Schematic arrangement of chemostat reactor. Numbers in the figure correspond to each part of the array as follow: 1) sterile media carboy, 2) culture media lines, 3) multiplexed peristaltic pump, 4)port manifold, 5) airlines, 6) air dehumidifier, 7) pump, 8) collection bottles for samples, 9) collection bottles for controls, 10) vessel with ports.

\subsubsection{Batch tests}

Batch tests were run using a microplate at similar conditions than those used during the chemostat tests. For both tests the ratio of bacteria/nanoparticle was kept constant. A $10 \mu \mathrm{L}$ of bacteria stock solution was inoculated into each of the six wells containing $5 \mathrm{~mL}$ of LB media. After approximately 7.5 hours, when the culture reached log phase with an OD670 was around 1 then AgNPs were injected to achieve the desire concentrations of $1 \mathrm{mg} / \mathrm{L}, 15 \mathrm{mg} / \mathrm{L}$ and $50 \mathrm{mg} / \mathrm{L}$. After the injection of the nanoparticles, the plates were incubated for 5 hours to assess the AgNPs effect on bacteria concentration. OD670 was determined using the same procedure described in the chemostat section. 


\subsubsection{Langmuir film balance}

The membranes of the bacteria were extracted before injection of the AgNPs and after 5 hours of exposure to the respective nanoparticle concentration in the chemostat. In the case, the batch tests samples collected at 5 hours were used for the extraction of the membrane. After bacteria membranes were extracted according to the protocol of Bligh and Dyer (Bligh and Dyer, 1959) lipid monolayers were analyzed by Langmuir film balance based on the surface pressure-area isotherms.

Lipid packing, based on the total area occupied by the lipid extract at the air/water interface at constant temperature, was altered with moveable barriers in a Langmuir film balance. All results are presented for compression isotherms. Surface pressure was calculated as $\pi=\gamma_{0}-\gamma$ where $\gamma_{0}$ is the air/water interfacial tension and $\gamma$ is the air/water/membrane extract (lipid) interfacial tension. The surface tensions were measured using a Wilhelmy plate (Figure 2).

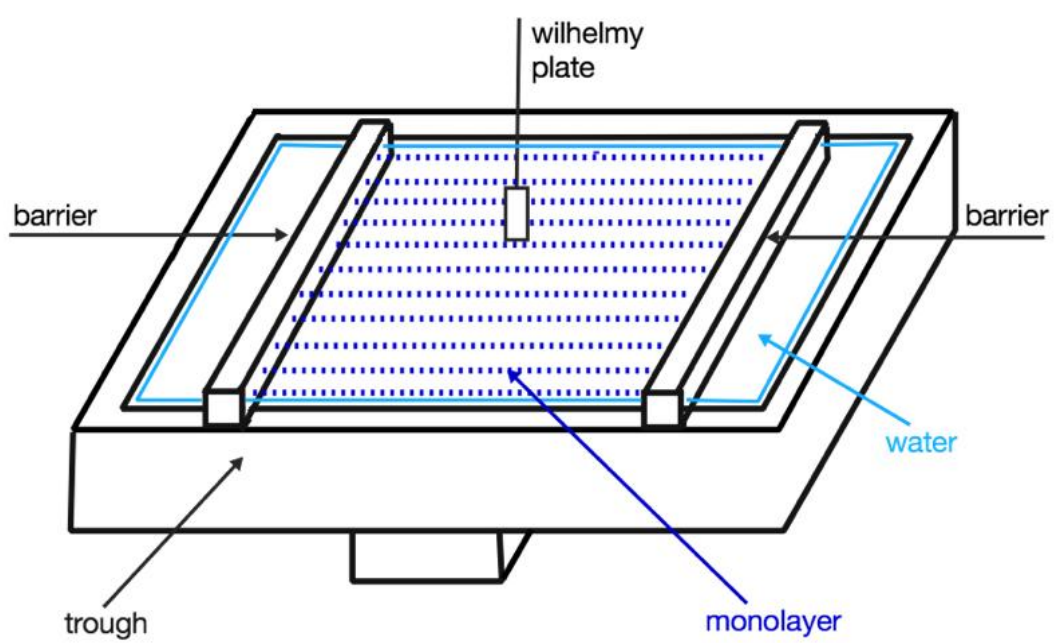

Figure 2: Langmuir-Blodgett system including the main parts: barrier, trough, monolayer, and Wilhelmy plate. 


\subsubsection{Epifluorescence staining membrane integrity test}

A membrane integrity test was also performed for the batch reactors to compare the permeability membrane and the surface pressure changes. The cell membrane permeation of $E$. coli was determined using the Backlight kit (propidium iodide and SYTO 9) with a microplate reader. Propidium iodide becomes intercalated to the DNA within cells, and indicates whether bacteria that have a damaged membrane while SYTO 9 indicates intact cell membranes (Boulos et al., 1999). A stain solution composed of SYTO 9 and propidium iodide fluorescent nucleic acid stains was mixed at a 1:1 (v/v) ratio with a subsequent dilution in DI water $(12 \mu \mathrm{L}$ of stain mixed solution in $2 \mathrm{~mL}$ of DI water). $100 \mu \mathrm{L}$ of bacteria samples from each of the six wells with a fixed OD670 of 0.06 were added to the wells of a 96 well flat-bottom black microplate. Thereafter, $100 \mu \mathrm{L}$ of mixed stain solution was added and mixed thoroughly by pipetting at least 10 times for each well. Before reading with the microplate, 15 min of additional incubation was required in the dark at room temperature. A calibration curve of live and dead bacteria was necessary to quantify and compare the membrane disruption on bacteria before and after nanoparticle exposure. Each plate contained triplicate wells for each condition, and each plate was run in duplicate to quantify the Undisturbed Cell Membrane (UCM). The UCM (Eq. 1) is the green/red fluorescence ratio between bacteria exposed to AgNPs and the blank bacteria (bacteria not exposed to AgNPs) at given AgNPs concentration. Data was analyzed after 5 hours of AgNPs exposure to quantify inhibitory effect of AgNPs on the bacteria.

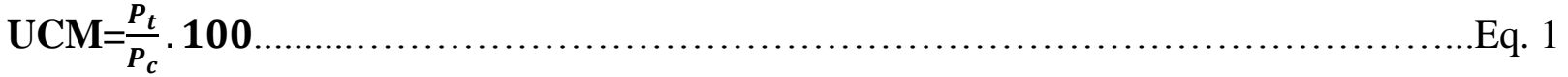
Where, $\mathrm{P}_{\mathrm{t}}=$ Green/red fluorescence ratio for bacteria exposed to AgNPs $\mathrm{P}_{\mathrm{c}}=$ Green/red fluorescence ratio for bacteria control without AgNPs
} 


\section{Results}

\subsection{Physicochemical characterization}

Characterizations of AgNPs consisted of size measurements in fresh media and bacteriafree media collected after 12 hours of bacterial growth (used growth media). The used growth media reduced the AgNPs stability producing aggregation. A concentration of $15 \mathrm{mg} / \mathrm{L} \mathrm{AgNPs}$ was the more suitable concentration to measure size, using the DLS, because $1 \mathrm{mg} / \mathrm{L}$ was too close to the lower detection limit and $50 \mathrm{mg} / \mathrm{L}$ was above the ideal range of the instrument. Figure 3 shows the average hydrodynamic diameter of the AgNPs suspended in different media between 0 hours and 9 hours for $15 \mathrm{mg} / \mathrm{L}$ of AgNPs. It is expected that at $50 \mathrm{mg} / \mathrm{L}$ higher sizes of aggregate will be formed in comparison to $15 \mathrm{mg} / \mathrm{L}$ due the greater number of nanoparticles in the solution, thus increasing the nanoparticle-nanoparticle interaction and, therefore, the possible aggregation of the nanoparticles. On the other hand, at $1 \mathrm{mg} / \mathrm{L}$ nanoparticles average size is expected to be similar than average size obtained at $15 \mathrm{mg} / \mathrm{L}$.

Controls of AgNPs suspended in DI water showed that nanoparticles were stable at a size of $44.8 \pm 1 \mathrm{~nm}$ and zeta potential measurements ranging between $-29.7 \mathrm{mV}$ and $-31.7 \mathrm{mV}$. Once AgNPs were contacted with LB media, the size slightly increased to $73.51 \pm 19 \mathrm{~nm}$. Likewise when AgNPs were contacted with used growth media aggregation of nanoparticles were detected. The size of AgNPs increased from $86 \mathrm{~nm}$ at time zero to $282 \mathrm{~nm}$ after 5 hours showing that exopolymeric substances (EPS) released during the bacterial growth (composed of lipids, proteins and nucleic acids) can affect the AgNPs stability and could influence the inhibitory effect. Joshi et al., 2012 showed that EPS can trap the AgNPs outside the membrane as protective mechanism and decrease the inhibitory effect on bacteria due to the less interaction between bacteria and nanoparticles. 
The dissolution of ions over time at room temperature was $1.2 \pm 0.2 \%$ of the total silver concentration for $15 \mathrm{mg} / \mathrm{L}$ in DI water.

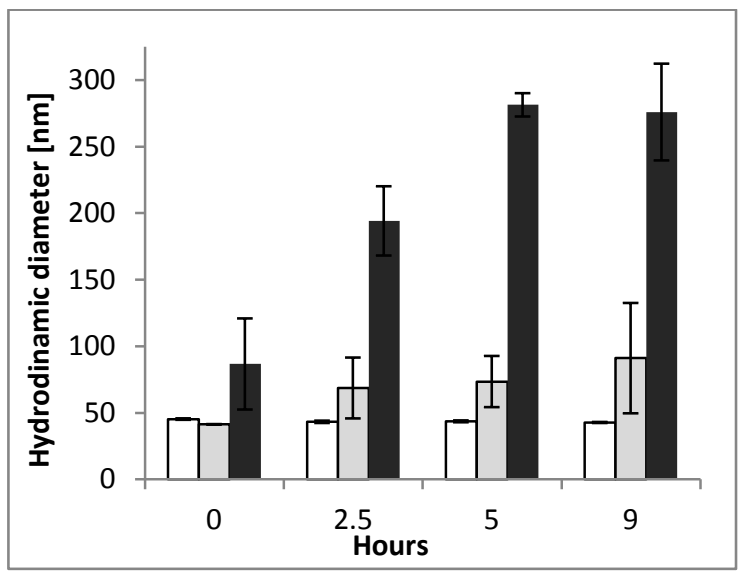

Figure 3: AgNPs stability in DI water, culture media and supernatant after 9hours for $15 \mathrm{mg} / \mathrm{L}$ of $\mathrm{AgNPs}$. Time measurements were taken at 0 hours, 2.5 hours, 5 hours and 9 hours for batch experiments. White markers represent AgNPs suspended in DI water, gray markers AgNPs suspended in fresh culture media and black markers correspond to AgNPs suspended in bacteria-free media collected after 12hours of $E$. coli growth

\subsection{Growth conditions}

\subsubsection{Chemostat}

Bacteria grew for 12.5 hours $(750 \mathrm{~min})$ until steady state conditions were reached in terms of OD670. At that time, AgNPs were injected only into the test bioreactors to achieve the desired concentrations $(1 \mathrm{mg} / \mathrm{L}, 15 \mathrm{mg} / \mathrm{L}$ or $50 \mathrm{mg} / \mathrm{L}$ corresponding approximately to 7:1, 105:1 and 350:1 AgNPs/bacteria ratios, respectively). Two bioreactors were used as controls, which contained bacteria without nanoparticles as controls to compare the growth rates between bacteria with and without exposure to nanoparticles, and two with only growth medium to detect possible contamination, and to study the interaction of AgNPs in the LB medium. Figure 4 shows the time when AgNPs were injected with a red arrow. Afterwards, the systems were operated for at least 5 additional hours (300 $\mathrm{min})$. The OD670 was measured to estimate bacteria concentration every 2.5 hours (150 $\mathrm{min})$. 


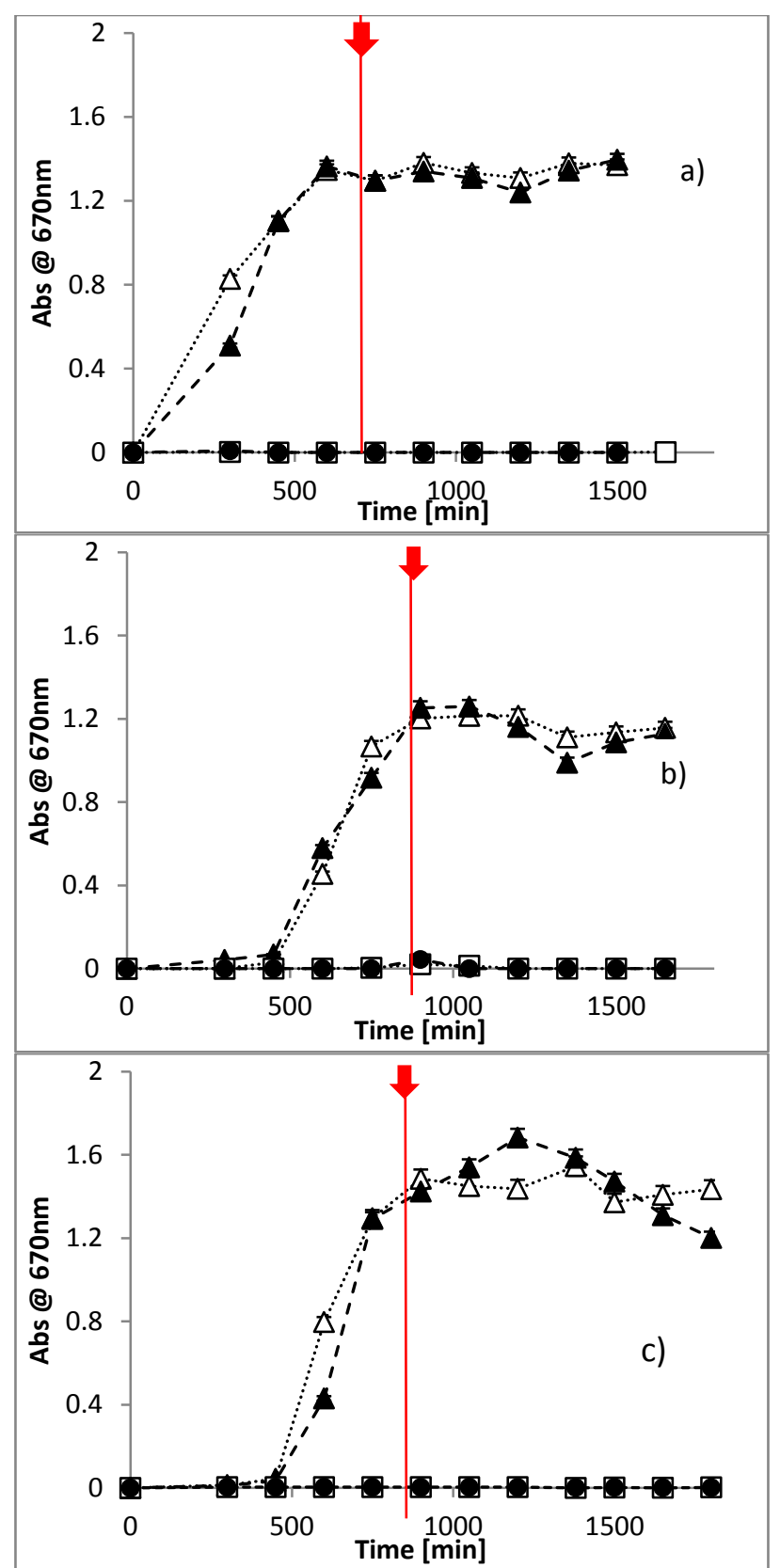

Figure 4: Growth of $E$. coli exposure to three AgNPs concentrations: a) $1 \mathrm{mg} / \mathrm{L}$, b) $15 \mathrm{mg} / \mathrm{L}$ and c) $50 \mathrm{mg} / \mathrm{L} \mathrm{in} \mathrm{the}$ chemostat reactors. $\Delta$ represents bacteria control without AgNPs. $\Delta$ represents bacteria control exposed to AgNPs. $\bullet$ represents a LB media control to detect contamination. $\square$ represents LB media exposed to AgNPs to study nanoparticles stability and control to quantify the OD670 from the AgNPs. The arrow and the red line show the time when AgNPs were injected into the system. OD670 was read every each 2.5 hours (150 min) after samples were re-suspended in PBS 10\%. Bars represent the error between duplicates

Only when the concentration of nanoparticles inside the chemostat was $50 \mathrm{mg} / \mathrm{L}$ a reduction on bacteria concentration was detected. In this case, a sustained decrease in OD670 (16.3\%) and COD (27.6\%) after AgNPs injection time was detected after 12.5 hours. OD670 increased after AgNPs injection time due to the nanosuspension brownish coloration at high 
AgNPs concentration. In the case of $15 \mathrm{mg} / \mathrm{L}$ a reduction on $11 \%$ of OD670 and $8 \%$ of COD were measured after 5 hours $(300 \mathrm{~min})$ of the AgNPs injection. However, recovery of the bacteria concentration was detected to similar OD670 and COD concentrations than those obtained before the injection of nanoparticles. No changes in terms of OD670 or COD were found at $1 \mathrm{mg} / \mathrm{L}$ AgNPs. These results showed an inversely correlation between AgNPs and bacteria concentrations.

AgNPs concentration was quantified after the injection in each reactor using the ICPOES. Figure 5 shows that the AgNPs were inside the bioreactors between 5 hours (300 min) and 7.5 hours (450 min) after AgNPs injection for all conditions, when 0 hours corresponds to the time right before the AgNPs injection.
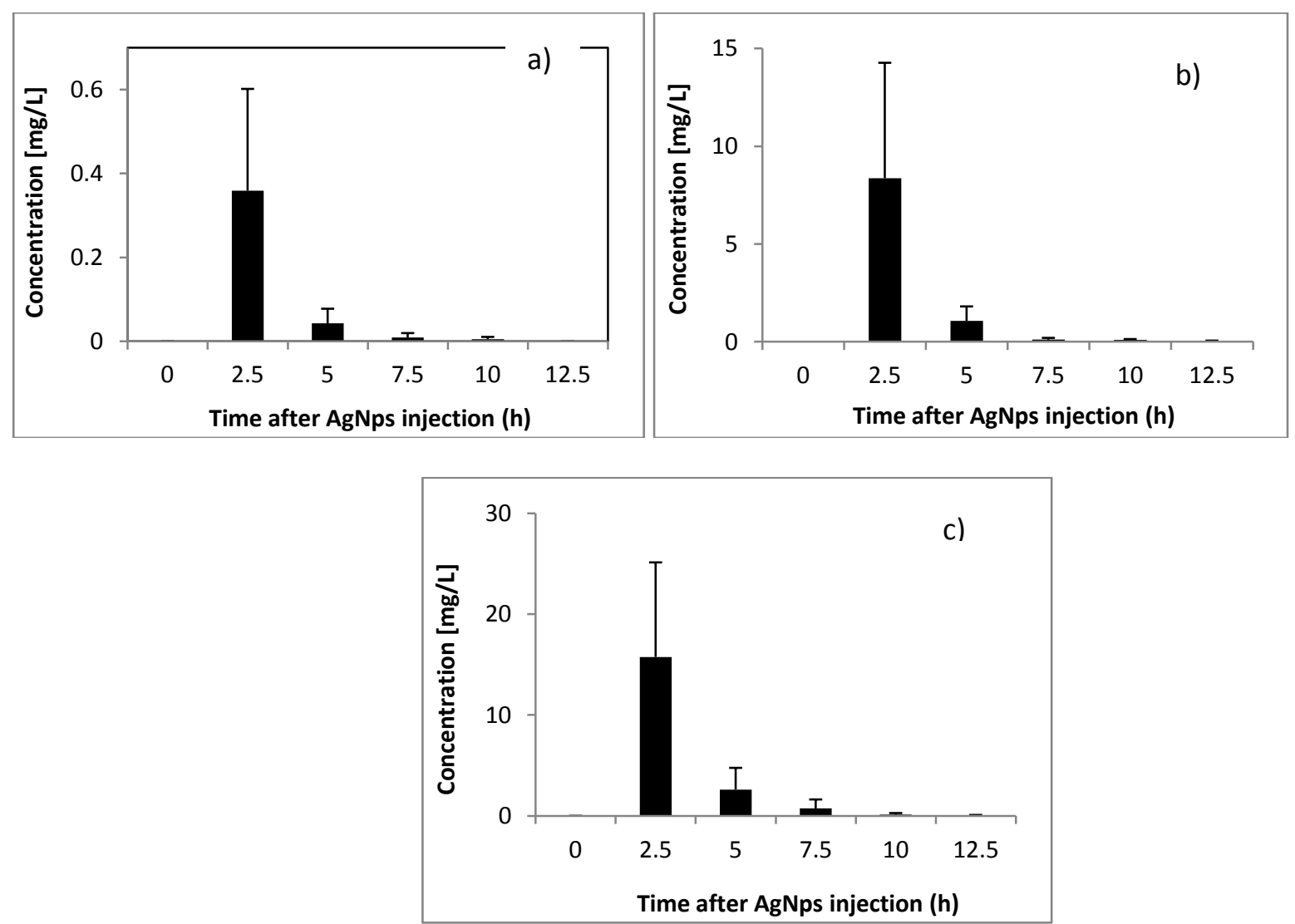

Figure 5: Average changes of AgNPs concentration inside of the chemostat bioreactors 12.5 hours after AgNPs injection a) $1 \mathrm{mg} / \mathrm{L}$, b) $15 \mathrm{mg} / \mathrm{L}$ and c) $50 \mathrm{mg} / \mathrm{L}$. Zero time (0 hours) corresponds right before AgNPs injection. Data based on duplicate experiments. 


\subsubsection{Batch}

Bacteria grew for 7.5 hours (450 min) until log phase was achieved. After that, AgNPs were injected to reach the required concentrations $(1 \mathrm{mg} / \mathrm{L}, 15 \mathrm{mg} / \mathrm{L}$ and $50 \mathrm{mg} / \mathrm{L})$ inside the microplate wells. Then, the test run for additional 5 hours (300 $\mathrm{min})$, which corresponds to hydraulic retention time (HRT) in the chemostat reactor (Figure 6).

Nevertheless, AgNPs concentration of $50 \mathrm{mg} / \mathrm{L}$ was not suitable for the batch tests due to the fast aggregation and sedimentation leading to false readings in the results. Details are presented in detail in the SI.

The AgNPs inhibition on bacteria measured through the ratio of slopes based on OD670 growth curves between bacteria exposed to AgNPs and the control bacteria (bacteria not exposed to AgNPs) were $20 \%$ and $0 \%$, at $1 \mathrm{mg} / \mathrm{L}$, and $15 \mathrm{mg} / \mathrm{L}$ of $\mathrm{AgNPs}$, respectively. These values showed that $1 \mathrm{mg} / \mathrm{L}$ was the condition that produced a slight reduction in terms of bacteria concentration, compared to the other conditions.

The EPS most likely accumulated inside the batch reactors (microplate wells) promoting destabilization and sedimentation of the nanoparticles on the bottom of the well. Furthermore, less interaction between AgNPs and bacteria at $15 \mathrm{mg} / \mathrm{L}$ due to high level of aggregation and sedimentation of AgNPs, can be the reason for the null or slight inhibitory effect detected. Additionally, AgNPs and the silver ions can be either chelated or coated by the EPS preventing the $\mathrm{Ag}^{+}$release. Figure 7 showed that EPS decrease the release of ions between 8 and 12 times for 50 and $15 \mathrm{mg} / \mathrm{L}(1 \mathrm{mg} / \mathrm{L}$ was not suitable for analysis because the concentration of ions was close to the ICP-OES detection limit) respectively, in comparison to Ag ions released into the culture media. 

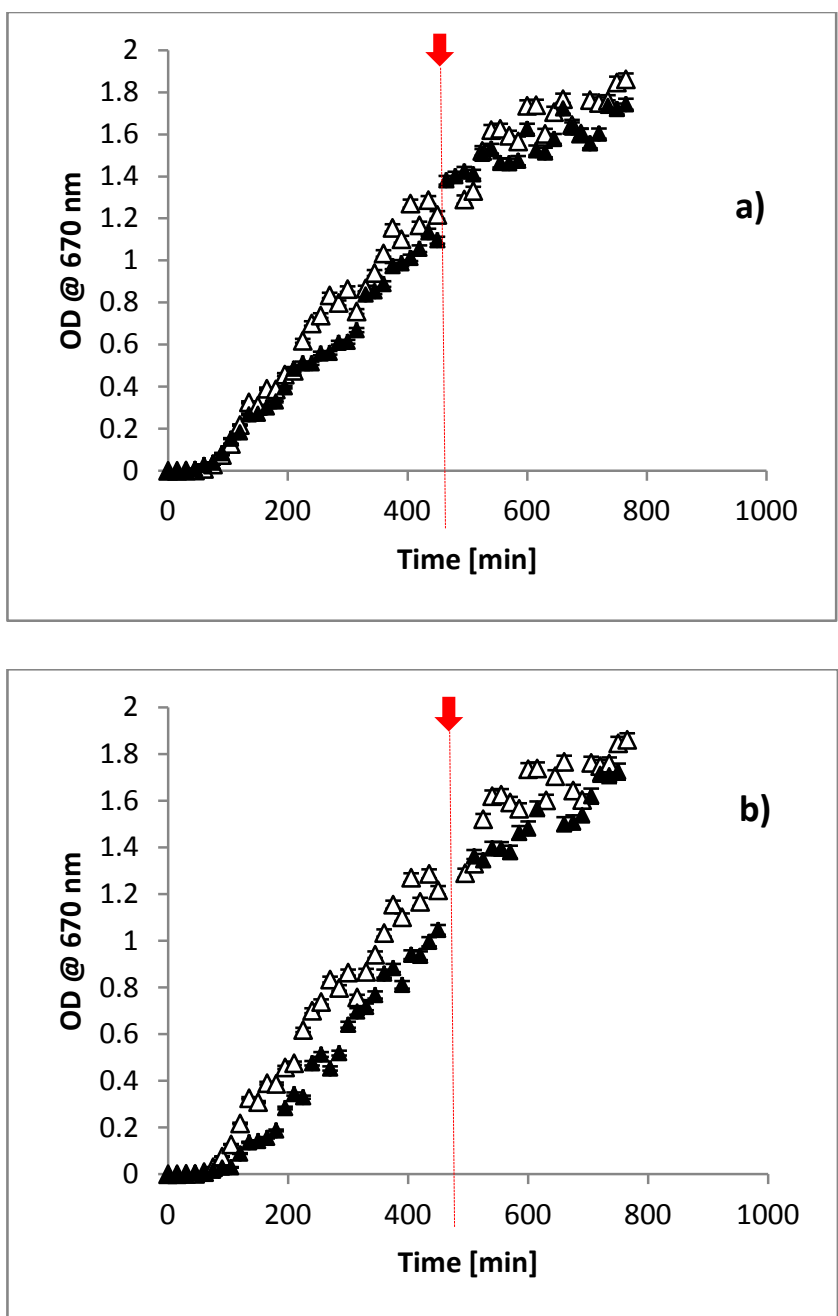

Figure 6: Growth of E. coli in exposure to two AgNPs concentration: a) $1 \mathrm{mg} / \mathrm{L}$, and b) $15 \mathrm{mg} / \mathrm{L}$ in the batch reactors. White triangles show the growth curve of bacteria growing in a AgNPs free culture, while black triangles show the growth curve of bacteria exposed to the respective concentration of AgNPs. The red arrow and line show the time of injection of the AgNPs into the system. OD670 was read each 15 min.

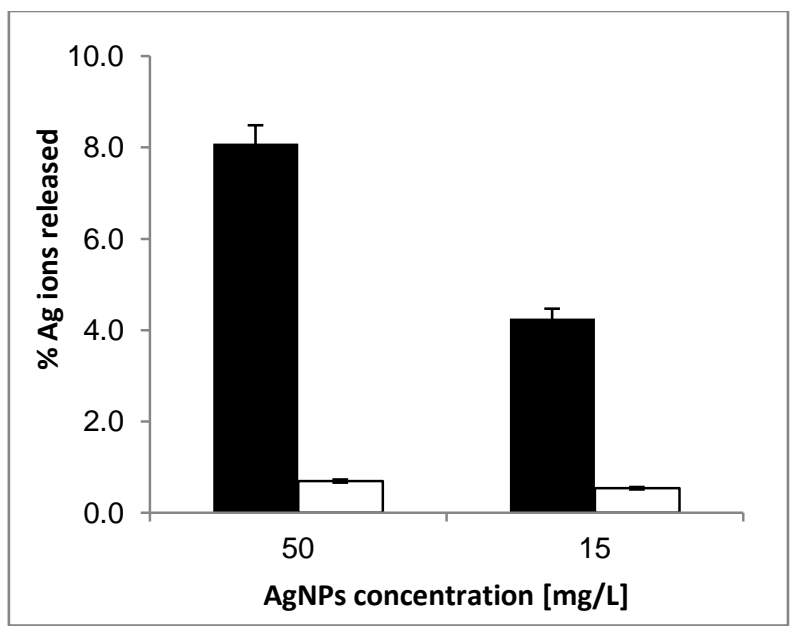

Figure 7: Percentage of silver ions released from AgNPs at concentrations of $50 \mathrm{mg} / \mathrm{L}$ and $15 \mathrm{mg} / \mathrm{L}$ suspended in freshly prepared culture media (black bars) and bacteria-free media collected after 12hours of E. coli growth (white bars). Values were collected after 5 hours of AgNPs-media contact time at $37^{\circ} \mathrm{C}$. Samples run in duplicate. 


\subsection{Surface pressure analysis of membrane extracts}

\subsubsection{Chemostat}

Surface pressure was calculated as $\pi=\gamma_{0}-\gamma$ where $\gamma_{0}$ was the air/water interfacial tension and $\gamma$ is the air/water/membrane extract (lipid) interfacial tension. Increases in $\pi$ in the presence of membrane lipids reflect a reduction in interfacial tension due to the surface-active properties of the lipids. Surface pressure-area $(\pi-\mathrm{A})$ isotherms were measured with compression, or decreasing A, at a constant mass of membrane lipids. By holding the lipid mass constant, differences in $\pi$ between cell culture experiments with and without AgNPs can be attributed to changes in lipid composition.

Figure 8 shows results for $\pi-\mathrm{A}$ isotherms conducted on membrane lipids obtained from chemostat cultures at AgNPs concentrations of $1 \mathrm{mg} / \mathrm{L}, 15 \mathrm{mg} / \mathrm{L}$, and $50 \mathrm{mg} / \mathrm{L}$. The increases in $\pi$ upon compression reflect a decrease in interfacial tension. At $1 \mathrm{mg} / \mathrm{L}$ and $15 \mathrm{mg} / \mathrm{L}$ the $\pi-\mathrm{A}$ isotherms where cells were exposed to AgNPs were shifted to lower areas relative to the control. In these cases, the lipid monolayers required more compression to achieve comparable surface pressures to the control. This result infers that the membrane lipids where cells were exposed to AgNPs were occupied less area at the air/water interface. The most plausible explanation for this observation is that the lipids from extracts where cells were exposed to AgNPs contained more saturated than unsaturated acyl tails. Lipids with saturated acyl tails do not exhibit "tail kinking" and occupy less interfacial area than lipids with unsaturated acyl tails do. At $50 \mathrm{mg} / \mathrm{L}$ there was no statistical difference in the $\pi-\mathrm{A}$ isotherms with and without AgNPs exposure. These results suggest that in chemostat cultures membrane disruption caused by AgNPs was a destabilizing or fluidizing (disordering) effect where the cells responded by shifting their lipid composition to more rigid, saturated lipids to counteract membrane fluidization. 


\subsubsection{Batch reactors}

\subsubsection{Langmuir Blodgett}

Figure $8 \mathrm{~b}$ shows the results for $\pi-\mathrm{A}$ isotherms conducted on membrane lipids obtained from batch cultures. At $15 \mathrm{mg} / \mathrm{L}$ and $50 \mathrm{mg} / \mathrm{L}$, the $\pi-\mathrm{A}$ isotherms where cells were exposed to AgNPs were shifted to higher areas relative to the control. In contrast to the results for membrane lipids from chemostat cultures, the lipid monolayers required less compression to achieve comparable surface pressures to the control, while the membrane lipids from the batch cultures occupied more area at the air/water interface. At $1 \mathrm{mg} / \mathrm{L}$ there was no difference in the $\pi-\mathrm{A}$ isotherms with and without AgNPs exposure. These results suggest that in batch cultures membrane disruption caused by AgNPs was a stabilizing or rigidifying (ordering) effect where the cells responded by shifting their lipid composition to more unsaturated lipids to counteract membrane rigidification.

Direct comparisons for membrane lipid monolayer behavior between chemostat and batch cultures are made based on the change in area, $\Delta \mathrm{A}=\mathrm{A}_{\mathrm{AgNPs}}-\mathrm{A}_{\text {control, }}$, at $5 \mathrm{mN} / \mathrm{m}$ (Figure 8c). For both conditions, $\Delta \mathrm{A}$ increases within increasing AgNPs concentration. The key difference between these conditions is that at $1 \mathrm{mg} / \mathrm{L}$ AgNPs there is little change for the chemostat cultures, while for batch cultures the greatest change was observed. 

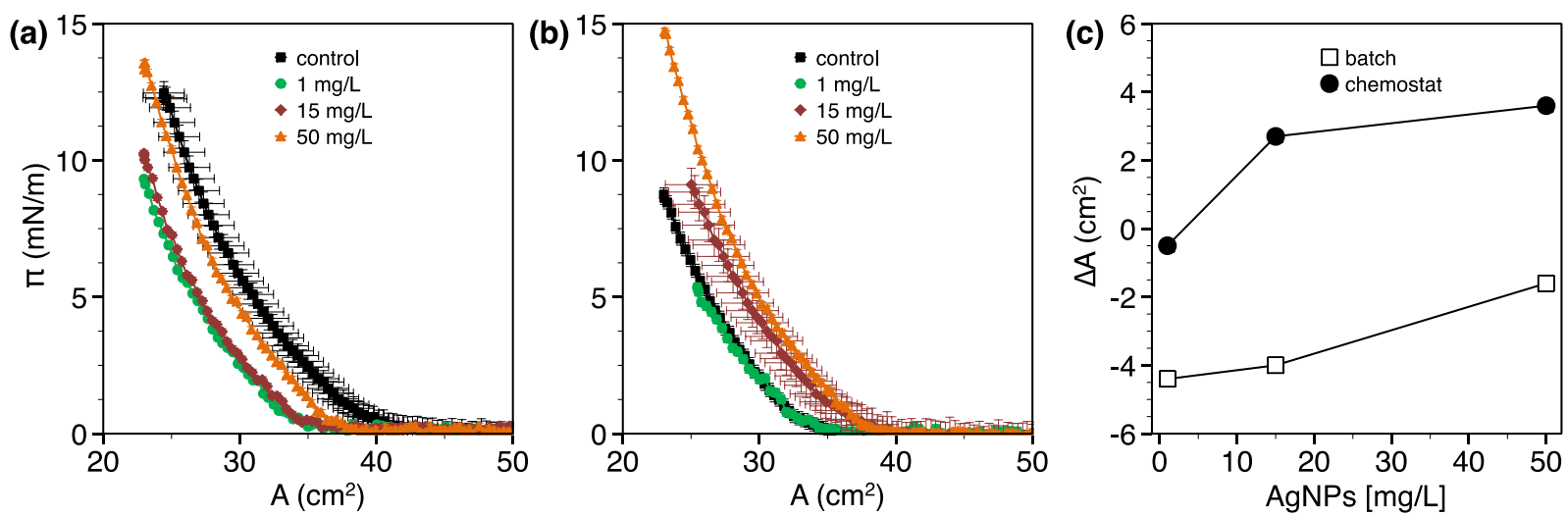

Figure 8: Surface pressure-area isotherms $(\pi-A)$ of membrane lipid extracts from (a) chemostat and (b) batch cultures exposed to nanoparticles at $1 \mathrm{mg} / \mathrm{L}, 15 \mathrm{mg} / \mathrm{L}$, and $50 \mathrm{mg} / \mathrm{L}$. Error bars represent average standard error for duplicate experiments. (c) Change in area as a function of nanoparticle concentration at $5 \mathrm{mN} / \mathrm{m}$ relative to the controls.

\subsubsection{Epifluorescence staining membrane integrity test}

Undisturbed cell membrane (UCM) results are displayed in Figure 9. Live/Dead experiments detected a very low inhibitory effect of AgNPs on E. coli after 5 hours. The results indicated no significant membrane permeation of the cell for AgNPs concentrations of $50 \mathrm{mg} / \mathrm{L}$ and $15 \mathrm{mg} / \mathrm{L}$ with UCM of 100 and $97 \%$, respectively. The previous results indicated minimal to no physical damage to E. coli between $15 \mathrm{mg} / \mathrm{L}$ and $50 \mathrm{mg} / \mathrm{L}$ of AgNPs. Only at low concentrations of AgNPs (1 mg/L) was a slight inhibitory effect (UCM=90.7\%) observed in bacteria. AgNPs aggregation at high concentrations and steric forces decrease due the EPS released during bacteria metabolism can decrease the AgNPs inhibitory effect on bacteria. Using $\mathrm{t}$ test, it was found a statistical difference between $1 \mathrm{mg} / \mathrm{L}$ and $50 \mathrm{mg} / \mathrm{L}(\mathrm{p}=0.026)$ and between $1 \mathrm{mg} / \mathrm{L}$ and $15 \mathrm{mg} / \mathrm{L},(\mathrm{p}=0.027)$, however no statistical difference was found between $15 \mathrm{mg} / \mathrm{l}$ and $50 \mathrm{mg} / \mathrm{L}(\mathrm{p}=0.152)$. The statistical analysis confirmed that low concentrations are a higher inhibitory effect in comparison with the high concentrations. 
Figure 9: Represents the undisturbed cell membrane of $E$. coli under AgNPs. Undisturbed cell membrane values were calculated for three concentrations of AgNPs, $1 \mathrm{mg} / \mathrm{L}, 15 \mathrm{mg} / \mathrm{L}$ and $50 \mathrm{mg} / \mathrm{L}$ at 5 hours. Each value represents an average of 4 wells from two duplicate plates.

\section{Discussion}

This study compared the use of chemostat and batch reactors to assess the casein coated AgNPs exposure to E. coli in terms of bacteria growth and surface tension changes. Conditions from chemostat reactors were replicated in the batch reactor to compare AgNPs inhibition effects in both systems.

In our study, it was found that there is only a small or null inhibitory effect at all the AgNPs concentration used in batch conditions. Therefore, these results differ from previous studies simulating natural water conditions (Zhang and Oyanedel-Craver, 2013; Mirzajani et al., 2011). This may be due that bacteria are growing condition (rather than non-growing in tests using natural water conditions) and a lower nanoparticle-bacteria ratio used in comparison to other studies (in other studies the same concentration of nanoparticles were added at the start of the batch culture were numbers of bacteria are very low). In addition, the EPS accumulation inside the bioreactors greatly affected the stability of AgNPs thus reducing the cell-nanoparticle interactions. The slight or null effect of AgNPs exposure to bacteria in batch cultures was also consistent with the membrane lipid monolayer results where AgNPs had a stabilizing effect on 
the E. coli membranes. Therefore batch conditions are not appropriate to evaluate the effect of nanoparticle exposure to bacteria for growth conditions.

In the case of chemostat reactors, the constant feeding and aeration seemed to increase the stability of nanosuspension compared to batch conditions. Constant inflow of fresh media could reduce the accumulation of EPS inside the reactor, while aeration could reduce the aggregation of nanoparticles and therefore increasing the contact between AgNPs and bacteria.

Greater inhibitory effect of AgNPs observed in chemostat cultures was consistent with the membrane lipid monolayer results that showed that AgNPs had a destabilizing effect which forced the bacteria to counteract this effect by synthesizing lipids that are known to strengthen cellular membranes. Langmuir Blodgett and epifluorescence staining membrane integrity test for batch conditions showed a similar trend. Here, $1 \mathrm{mg} / \mathrm{L}$ of AgNPs had a higher inhibitory effect on bacteria compared to $15 \mathrm{mg} / \mathrm{L}$ and $50 \mathrm{mg} / \mathrm{L}$ of AgNPs.

\section{CONCLUSIONS}

This study shows that chemostat systems can be used to provide a better and more comprehensive assessment of the nanoparticle inhibitory effects on microorganisms compared to batch systems at growing conditions. Langmuir Blodgett was used to evaluate the surface tension changes in bacterial membranes, this test provided additional information to the staining membrane integrity test. The formation of EPS during the growth of E. coli influenced the level of the AgNPs effect on the cell membranes, and therefore the bacterial growth. With an understanding of the fate of nanoparticles in aqueous media, a more careful selection of appropriate toxicological methodologies and testing conditions can be made. This will allow for 
nanoparticles.

\section{ACKNOWLEDGMENTS}

This research work was supported by the National Science Foundation under the grant numbers CBET-1350789 and CBET-1055652.

\section{REFERENCES}

Anaya, N.M., Solomon, F., Oyanedel-Craver, V., 2015. Effects of dysprosium oxide nanoparticles on Escherichia coli. Environ. Sci. Nano. doi:10.1039/C5EN00074B

Bligh, E.G., Dyer, W.J., 1959. A Rapid Method of Total Lipid Extraction and Purification. Can. J. Biochem. Physiol. 37, 911-917. doi:10.1139/o59-099

Bothun, G.D., Boltz, L., Kurniawan, Y., Scholz, C., 2016. Cooperative effects of fatty acids and n-butanol on lipid membrane phase behavior. Colloids Surf. B Biointerfaces 139, 62-67. doi:10.1016/j.colsurfb.2015.11.054

Boulos, L., Prévost, M., Barbeau, B., Coallier, J., Desjardins, R., 1999. LIVE/DEAD® BacLight ${ }^{\mathrm{TM}}$ : application of a new rapid staining method for direct enumeration of viable and total bacteria in drinking water. J. Microbiol. Methods 37, 77-86. doi:10.1016/S0167-7012(99)00048-2

Choi, O., Deng, K.K., Kim, N.-J., Ross Jr., L., Surampalli, R.Y., Hu, Z., 2008. The inhibitory effects of silver nanoparticles, silver ions, and silver chloride colloids on microbial growth. Water Res. 42, 3066-3074. doi:10.1016/j.watres.2008.02.021

Eckhardt, S., Brunetto, P.S., Gagnon, J., Priebe, M., Giese, B., Fromm, K.M., 2013. Nanobio Silver: Its Interactions with Peptides and Bacteria, and Its Uses in Medicine. Chem. Rev. 113, 4708-4754. doi: $10.1021 / \mathrm{cr} 300288 \mathrm{v}$

Gresham, D., Hong, J., 2015. The functional basis of adaptive evolution in chemostats. FEMS Microbiol. Rev. 39, 2-16. doi:10.1111/1574-6976.12082

Guzmán, E., Liggieri, L., Santini, E., Ferrari, M., Ravera, F., 2013. Mixed DPPC-cholesterol Langmuir monolayers in presence of hydrophilic silica nanoparticles. Colloids Surf. B Biointerfaces 105, 284-293. doi:10.1016/j.colsurfb.2013.01.020

Guzmán, E., Liggieri, L., Santini, E., Ferrari, M., Ravera, F., 2012. Influence of silica nanoparticles on dilational rheology of DPPC-palmitic acid Langmuir monolayers. Soft Matter 8, 3938-3948. doi:10.1039/C2SM07097A

Joshi, N., Ngwenya, B.T., French, C.E., 2012. Enhanced resistance to nanoparticle toxicity is conferred by overproduction of extracellular polymeric substances. J. Hazard. Mater. 241-242, 363-370. doi:10.1016/j.jhazmat.2012.09.057

Kasaraneni, V.K., Schifman, L.A., Boving, T.B., Oyanedel-Craver, V., 2014. Enhancement of Surface Runoff Quality Using Modified Sorbents. ACS Sustain. Chem. Eng. 2, 1609-1615. doi:10.1021/sc500107q

King, T., Seeto, S., Ferenci, T., 2006. Genotype-by-Environment Interactions Influencing the Emergence of rpoS Mutations in Escherichia coli Populations. Genetics 172, 2071-2079. doi:10.1534/genetics.105.053892 
Kurniawan, Y., Scholz, C., Bothun, G.D., 2013. n-Butanol Partitioning into Phase-Separated Heterogeneous Lipid Monolayers. Langmuir 29, 10817-10823. doi:10.1021/la400977h

Kvitek, L., Vanickova, M., Panacek, A., Soukupova, J., Dittrich, M., Valentova, E., Prucek, R., Bancirova, M., Milde, D., Zboril, R., 2009. Initial Study on the Toxicity of Silver Nanoparticles (NPs) against Paramecium caudatum. J. Phys. Chem. C 113, 4296-4300. doi:10.1021/jp808645e

Leenheer, P.D., Cogan, N.G., 2008. Failure of antibiotic treatment in microbial populations. J. Math. Biol. 59, 563-579. doi:10.1007/s00285-008-0243-6

Lin, M., Huo, H.-F., Li, Y.-N., 2012. A competitive model in a chemostat with nutrient recycling and antibiotic treatment. Nonlinear Anal. Real World Appl. 13, 2540-2555. doi:10.1016/j.nonrwa.2012.02.016

Li, Q., Mahendra, S., Lyon, D.Y., Brunet, L., Liga, M.V., Li, D., Alvarez, P.J.J., 2008. Antimicrobial nanomaterials for water disinfection and microbial control: Potential applications and implications. Water Res. 42, 4591-4602. doi:10.1016/j.watres.2008.08.015

Liu, J., Hurt, R.H., 2010. Ion Release Kinetics and Particle Persistence in Aqueous Nano-Silver Colloids. Environ. Sci. Technol. 44, 2169-2175. doi:10.1021/es9035557

Losasso, C., Belluco, S., Cibin, V., Zavagnin, P., MiÄ $\square$ etiÄł, I., Gallocchio, F., Zanella, M., Bregoli, L., Biancotto, G., Ricci, A., 2014. Antibacterial activity of silver nanoparticles: sensitivity of different Salmonella serovars. Front. Microbiol. 5. doi:10.3389/fmicb.2014.00227

Manke, A., Wang, L., Rojanasakul, Y., Manke, A., Wang, L., Rojanasakul, Y., 2013. Mechanisms of Nanoparticle-Induced Oxidative Stress and Toxicity, Mechanisms of Nanoparticle-Induced Oxidative Stress and Toxicity. BioMed Res. Int. BioMed Res. Int. 2013, 2013, e942916. doi:10.1155/2013/942916, 10.1155/2013/942916

Marambio-Jones, C., Hoek, E.M.V., 2010. A review of the antibacterial effects of silver nanomaterials and potential implications for human health and the environment. J. Nanoparticle Res. 12, 15311551. doi:10.1007/s11051-010-9900-y

Miller, A.W., Befort, C., Kerr, E.O., Dunham, M.J., 2013. Design and use of multiplexed chemostat arrays. J. Vis. Exp. JoVE e50262. doi:10.3791/50262

Mirzajani, F., Ghassempour, A., Aliahmadi, A., Esmaeili, M.A., 2011. Antibacterial effect of silver nanoparticles on Staphylococcus aureus. Res. Microbiol. 162, 542-549. doi:10.1016/j.resmic.2011.04.009

Panyala, N.R., Pena-Méndez, E.M., Havel, J., 2008. REVIEW: Silver or silver nanoparticles: A hazardous threat to the environment and human health? 2008.

Peetla, C., Labhasetwar, V., 2008. Biophysical Characterization of Nanoparticle-Endothelial Model Cell Membrane Interactions. Mol. Pharm. 5, 418-429. doi:10.1021/mp700140a

Prabhu, S., Poulose, E.K., 2012. Silver nanoparticles: mechanism of antimicrobial action, synthesis, medical applications, and toxicity effects. Int. Nano Lett. 2, 1-10. doi:10.1186/2228-5326-2-32

Pratap Reddy, M., Venugopal, A., Subrahmanyam, M., 2007. Hydroxyapatite-supported Ag-TiO2 as Escherichia coli disinfection photocatalyst. Water Res. 41, 379-386. doi:10.1016/j.watres.2006.09.018

Rai, M.K., Deshmukh, S.D., Ingle, A.P., Gade, A.K., 2012. Silver nanoparticles: the powerful nanoweapon against multidrug-resistant bacteria: Activity of silver nanoparticles against MDR bacteria. J. Appl. Microbiol. 112, 841-852. doi:10.1111/j.1365-2672.2012.05253.x

Reddy, C.A., Beveridge, T.J., Breznak, J.A., Marzluf, G., 2007. Methods for General and Molecular Microbiology. American Society for Microbiology Press.

Roe, D., Karandikar, B., Bonn-Savage, N., Gibbins, B., Roullet, J.-B., 2008. Antimicrobial surface functionalization of plastic catheters by silver nanoparticles. J. Antimicrob. Chemother. 61, 869876. doi:10.1093/jac/dkn034

Schifman, L.A., Kasaraneni, V.K., Sullivan, R.K., Oyanedel-Craver, V., Boving, T.B., 2015. New Antimicrobially Amended Media for Improved Nonpoint Source Bacterial Pollution Treatment. Environ. Sci. Technol. 49, 14383-14391. doi:10.1021/acs.est.5b03782 
Sondi, I., Salopek-Sondi, B., 2004. Silver nanoparticles as antimicrobial agent: a case study on E. coli as a model for Gram-negative bacteria. J. Colloid Interface Sci. 275, 177-182. doi:10.1016/j.jcis.2004.02.012

Torrano, A.A., Pereira, Â.S., Oliveira, O.N., Barros-Timmons, A., 2013. Probing the interaction of oppositely charged gold nanoparticles with DPPG and DPPC Langmuir monolayers as cell membrane models. Colloids Surf. B Biointerfaces 108, 120-126. doi:10.1016/j.colsurfb.2013.02.014

Venieri, D., Fraggedaki, A., Kostadima, M., Chatzisymeon, E., Binas, V., Zachopoulos, A., Kiriakidis, G., Mantzavinos, D., 2014. Solar light and metal-doped TiO2 to eliminate water-transmitted bacterial pathogens: Photocatalyst characterization and disinfection performance. Appl. Catal. B Environ. 154-155, 93-101. doi:10.1016/j.apcatb.2014.02.007

Venkataramanan, K.P., Kurniawan, Y., Boatman, J.J., Haynes, C.H., Taconi, K.A., Martin, L., Bothun, G.D., Scholz, C., 2014. Homeoviscous response of Clostridium pasteurianum to butanol toxicity during glycerol fermentation. J. Biotechnol. 179, 8-14. doi:10.1016/j.jbiotec.2014.03.017

Wood, J.M., 2015. Bacterial responses to osmotic challenges. J. Gen. Physiol. 145, 381-388. doi:10.1085/jgp.201411296

Zhang, H., Oyanedel-Craver, V., 2013. Comparison of the bacterial removal performance of silver nanoparticles and a polymer based quaternary amine functiaonalized silsesquioxane coated pointof-use ceramic water filters. J. Hazard. Mater. 260, 272-277. doi:10.1016/j.jhazmat.2013.05.025

Zhang, H., Oyanedel-Craver, V., 2012. Evaluation of the Disinfectant Performance of Silver Nanoparticles in Different Water Chemistry Conditions. J. Environ. Eng. 138, 58-66. doi:10.1061/(ASCE)EE.1943-7870.0000460

Zhang, H., Smith, J.A., Oyanedel-Craver, V., 2012. The effect of natural water conditions on the antibacterial performance and stability of silver nanoparticles capped with different polymers. Water Res. 46, 691-699. doi:10.1016/j.watres.2011.11.037

Ziv, N., Brandt, N.J., Gresham, D., 2013. The use of chemostats in microbial systems biology. J. Vis. Exp. JoVE. doi:10.3791/50168 


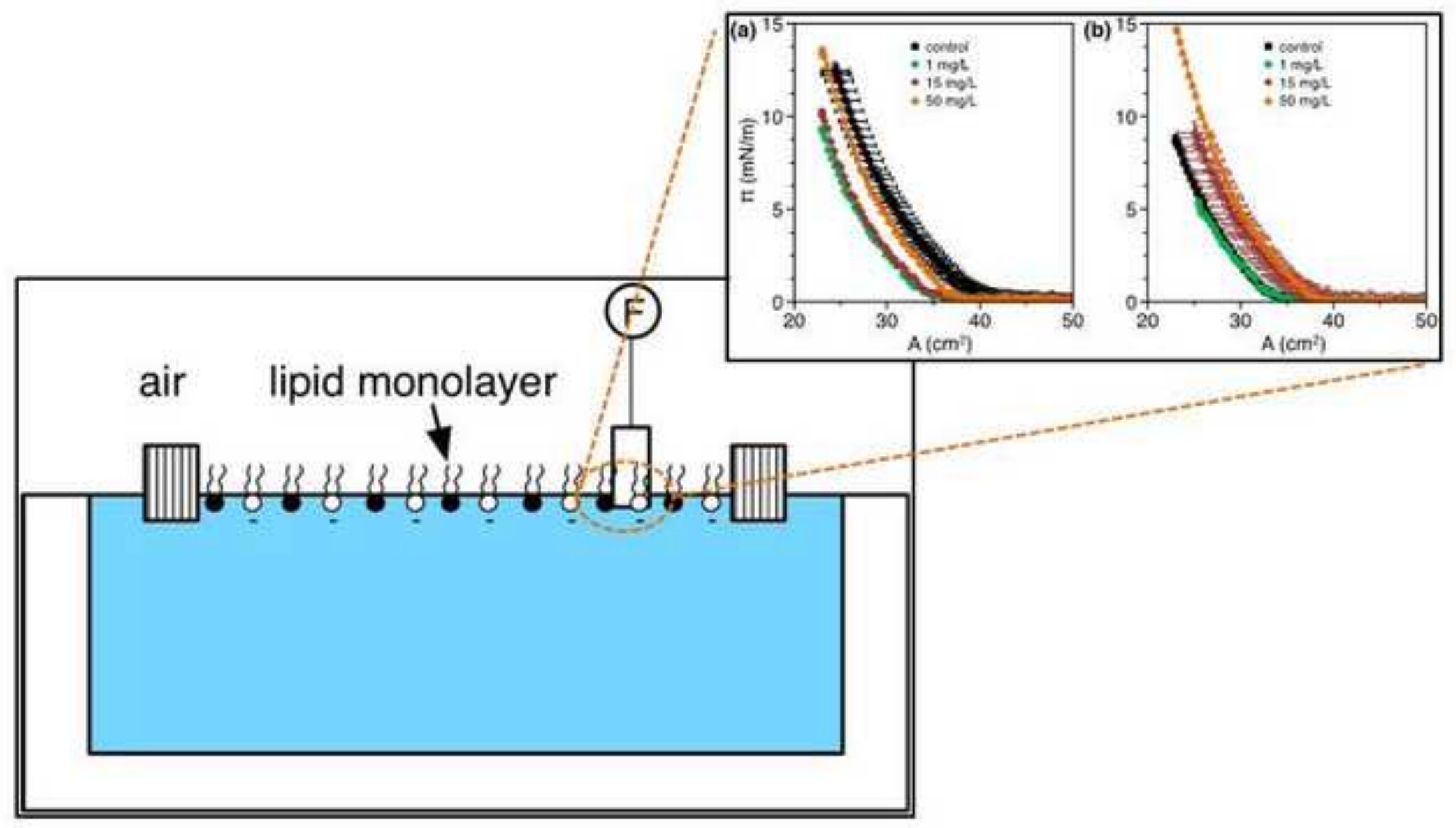

